Article (refereed) - postprint

Suggitt, Andrew J.; Wilson, Robert J.; Isaac, Nick J.B.; Beale, Colin M.;

Auffret, Alistair G.; August, Tom; Bennie, Jonathan J.; Crick, Humphrey Q.P.; Duffield, Simon; Fox, Richard; Hopkins, John J.; Macgregor, Nicholas A.; Morecroft, Mike D.; Walker, Kevin J.; Maclean, Ilya M.D.. 2018. Extinction risk from climate change is reduced by microclimatic buffering. Nature Climate Change, 8 (8). 713-717. https://doi.org/10.1038/s41558-018-0231-9

(C) 2018 Springer Nature Limited

This version available http://nora.nerc.ac.uk/id/eprint/520633/

NERC has developed NORA to enable users to access research outputs wholly or partially funded by NERC. Copyright and other rights for material on this site are retained by the rights owners. Users should read the terms and conditions of use of this material at http://nora.nerc.ac.uk/policies.html\#access

This document is the author's final manuscript version of the journal article, incorporating any revisions agreed during the peer review process. There may be differences between this and the publisher's version. You are advised to consult the publisher's version if you wish to cite from this article.

www.nature.com/ noraceh@ceh.ac.uk 


\section{Extinction risk from climate change is reduced by microclimatic buffering}

Andrew J. Suggitt ${ }^{1,2, *}$, Robert J. Wilson ${ }^{3, *}$, Nick J.B. Isaac ${ }^{4}$, Colin M. Beale ${ }^{2}$, Alistair G. Auffret $^{5,6}$, Tom August ${ }^{4}$, Jonathan J. Bennie ${ }^{1}$, Humphrey Q. P. Crick ${ }^{7}$, Simon Duffield ${ }^{7}$, Richard Fox $^{8}$, John J. Hopkins ${ }^{1}$, Nicholas A. Macgregor ${ }^{7,9}$, Mike D. Morecroft ${ }^{7}$, Kevin J. Walker $^{10}$ and Ilya M. D. Maclean ${ }^{1, *}$.

Manuscript ID: NCLIM-17040609B.

Length of revised main text: 2,030 words.

Length of Methods: 2,518 words.

Length of Fig. 1 legend text: 105 words.

Length of Fig. 2 legend text: 121 words.

Number of references: 30 .

Number of figures: 2 .

Fig. 1 estimated size: $1 / 2$ page A4 landscape.

Fig. 2 estimated size: $1 / 2$ page A4 portrait. 


\section{Extinction risk from climate change is reduced by microclimatic buffering}

Andrew J. Suggitt ${ }^{1,2, *}$, Robert J. Wilson ${ }^{3, *}$, Nick J.B. Isaac ${ }^{4}$, Colin M. Beale ${ }^{2}$, Alistair G. Auffret $^{5,6}$, Tom August ${ }^{4}$, Jonathan J. Bennie ${ }^{1}$, Humphrey Q. P. Crick ${ }^{7}$, Simon Duffield ${ }^{7}$, Richard Fox $^{8}$, John J. Hopkins ${ }^{1}$, Nicholas A. Macgregor ${ }^{7,9}$, Mike D. Morecroft ${ }^{7}$, Kevin J. Walker $^{10}$ and Ilya M. D. Maclean ${ }^{1, *}$.

*Corresponding authors: andrew.suggitt@york.ac.uk, r.j.wilson@exeter.ac.uk, i.m.d.maclean@exeter.ac.uk.

1 Environment and Sustainability Institute, College of Life and Environmental Sciences, University of Exeter, Penryn Campus, Penryn, Cornwall, TR10 9FE, UK.

2 Department of Biology, University of York, Wentworth Way, York, YO10 5DD, UK. 3 Biosciences, College of Life and Environmental Sciences, University of Exeter, Prince of Wales Road, Exeter, EX4 4PS, UK.

4 Centre for Ecology and Hydrology, Maclean Building, Benson Lane, Crowmarsh Gifford, Wallingford, Oxfordshire, OX10 8BB, UK.

5 Department of Ecology, Swedish University of Agricultural Sciences, 75007 Uppsala, Sweden.

6 Biogeography and Geomatics, Department of Physical Geography, Stockholm University, 10691 Stockholm, Sweden.

7 Natural England, Cromwell House, 15 Andover Road, Winchester, Hampshire, SO23 7BT, UK.

8 Butterfly Conservation, Manor Yard, East Lulworth, Wareham, Dorset, BH20 5QP, UK.

9 Durrell Institute of Conservation and Ecology, School of Anthropology and Conservation, University of Kent, Canterbury, Kent, CT2 7NR, UK.

10 Botanical Society of Britain and Ireland, 57 Walton Road, Shirehampton, Bristol, BS11 9TA, UK. 
1 Protecting biodiversity against the impacts of climate change requires effective conservation strategies that safeguard species at risk of extinction ${ }^{1}$. Microrefugia allowed populations to survive adverse climatic conditions in the past ${ }^{2,3}$, yet their potential to reduce extinction risk from anthropogenic warming is poorly understood ${ }^{3-5}$, hindering our capacity to develop robust in situ measures to adapt conservation to climate change ${ }^{6}$. Here we show that microclimatic heterogeneity strongly buffered species against regional extirpations linked to recent climate change. Using more than five million distribution records for 430 climate-threatened and range-declining species, population losses across England are found to be reduced in areas where topography generated greater variation in the microclimate. The buffering effect of topographic microclimates was strongest for those species adversely affected by warming, and in areas that experienced the highest levels of warming: in such conditions, extirpation risk was reduced by $22 \%$ for plants and by $9 \%$ for insects. Our results indicate the critical role of topographic variation in creating microrefugia, and provide empirical evidence that microclimatic heterogeneity can substantially reduce extinction risk from climate change.

Bioclimate modelling predicts that anthropogenic climate change will increase extinction risk for a wide range of taxa and regions ${ }^{7}$. However, there is a marked discrepancy between the coarse spatial scales at which geographic range contractions are commonly modelled, and the fine spatial scales at which most organisms respond to climatic variation.

This has important implications for estimating the vulnerability of species to climate change ${ }^{8}$ and, in consequence, for developing effective adaptation measures. Coarse-scale models fail to identify the localised effects of topography and vegetation on climate that were vital for sustaining refugial populations during past periods of climate change, and which could influence biological responses to current warming ${ }^{4}$. If landscape features promoting 
microclimatic heterogeneity allow species to persist under current climate change in situ, then

protection and appropriate management of such features is likely to be an important complement to conservation approaches, such as enhanced landscape connectivity or species translocations, that have been more widely advocated to accommodate range shifts ${ }^{1,9}$. However, the potential role of microclimatic heterogeneity to act as a buffer against the adverse effects of climate change is yet to be established for a wide range of species ${ }^{10}$. Here, we provide an empirical test of the extent to which microclimatic heterogeneity arising from landscape topography has buffered plants and insects in England against extirpations associated with recent climate change. To establish patterns of extirpation for each species during a period of warming, we compared distributions between two periods with comprehensive recording effort (1970-1986 and 1987-2009 for plants; 1970-1989 and 1990-2009 for insects). Our analyses focused on the well-recorded groups of Tracheophyta (vascular plants), Bryophyta (mosses and liverworts), Lepidoptera (butterflies and moths) and Coleoptera (beetles), and were restricted to recently declining species that have also been identified as being vulnerable to future climate warming ${ }^{11}$. We selected only species with records of persistence or extirpation in more than 100 unique $10 \times 10 \mathrm{~km}$ grid squares (the common unit of UK distribution atlases, and our unit of analysis - see Methods), giving a total of 430 species (316 plants and 114 insects). We defined the 'extirpation' of a species from a grid square if that species was recorded as present during the first period but not the second. Because we were only analysing persistence and extirpation (and not colonisations), we do not expect an observed increase in recorder effort through time to have biased our results. Nevertheless, to account for spatial variation in recorder effort, we included the total number of unique recorder visits to each grid square as a control in all models (Supplementary Figs. $1 \& 2$ ). To represent the warming rate in each $10 \mathrm{~km}$ grid square we calculated change in summer temperature over the study period (1970-2009), using monthly 
gridded data from the UK Met Office. To represent microclimatic heterogeneity arising from

52

53

54

55 the topography (hereafter simply 'microclimatic heterogeneity'), we calculated the proportion of direct beam solar radiation incident on the surface ${ }^{12}$ of each component $100 \times 100 \mathrm{~m}$ cell, before computing the standard deviation in these values across each $10 \mathrm{~km}$ grid square. The use of solar radiation as a proxy for thermal microclimate is a well-established means of analysing wildlife responses to fine-scale temperature variation ${ }^{13}$, because variation in the radiation budget associated with topography is one of the most important determinants of the temperature of terrestrial ecosystems at temperate latitudes ${ }^{14}$. However, to further demonstrate the validity of our proxy of microclimate, we compared it with modelled finescale temperature across $261 \mathrm{~km}^{2}$ of south-western England, showing that the two are closely related (Supplementary Figs. 3 \& 4). We modelled persistence versus extirpation for each species in each $10 \mathrm{~km}$ square as a function of warming rate, microclimatic heterogeneity, and the interaction between these factors. All our models also included controls for recorder effort, agricultural intensity, nitrogen deposition, mean elevation, precipitation change, and spatial autocorrelation (see Methods).

To assess the importance of microclimatic heterogeneity in buffering extirpations from climate change, we classified each species by its responses to warming, microclimatic heterogeneity and their interaction (Fig. 1). Of the plant species showing effects of warming, more than two thirds responded negatively (Fig. 1a). In contrast, most insect species responded positively to warming (Fig. 1a). Of those species that responded negatively to warming, the majority responded positively to microclimatic heterogeneity (Fig. 1b). Crucially, $59 \%$ of species affected by an interaction between warming and microclimatic heterogeneity benefitted from the microclimatic buffering effect (Fig. 1c). Species that were negatively affected by warming were also more likely to benefit (Fig. 1c). In contrast, for those species positively affected by warming, the relationships with microclimatic 
heterogeneity were more idiosyncratic (Fig. 1c), emphasising that microclimatic heterogeneity did not necessarily reduce probability of extirpation unless there was an adverse effect of warming.

To establish the extent to which microclimatic buffering modified extirpation risk, we used the full models for each species to estimate the effect of high vs. low microclimatic heterogeneity $\left(95^{\text {th }}\right.$ and $5^{\text {th }}$ percentiles respectively) on the likelihood of extirpation across the range of warming rates experienced in the study region (Fig. 2a). We found that the reduction in modelled extirpation risk between low and high microclimatic heterogeneity was greater with higher rates of warming, and for species showing stronger negative effects of warming (Fig. 2b, c, g, h). Microclimatic heterogeneity was estimated to have no effect on extirpation risk where warming was low (Fig. $2 \mathrm{f}$, $\mathrm{k}$; a median change in risk of $0 \%$ for both plants and insects). With the highest observed rates of warming, microclimatic heterogeneity was estimated to reduce extirpation risk of plants by a median of $16 \%$, though no such effect was predicted for insects (median 0\%; Fig. 2g). However, for the subset of species that responded negatively to warming, high microclimatic heterogeneity reduced extirpation risk by a median of $22 \%$ for plants and $9 \%$ for insects relative to low microclimatic heterogeneity. These estimated reductions in extirpation risk at high levels of warming suggest that microclimatic buffering is greatest for species and regions with greater exposure to climate warming, and implies that the effects of topographic microclimates on persistence will become more important as temperatures increase over time.

While the patterns of extirpations observed in this study are associated with a variety of drivers of environmental change, none of these drivers explain the disproportionate benefit of heterogeneous topographic microclimates for species negatively affected by warming, and at locations experiencing higher rates of warming. For example, though availability of seminatural habitat affects exposure to climate change $\mathrm{e}^{15}$, and $20^{\text {th }}$ century agricultural 
intensification has been greatest in flat, lowland areas of England ${ }^{16}$, our results were robust to the inclusion of an agricultural intensity control in all analyses. Other drivers of microclimatic variability ( such as the structure and cover of vegetation ${ }^{17}$ ) can have a substantial effect on the temperatures that organisms experience ${ }^{18}$, and thus also have the potential to buffer species against macroclimatic change. Nitrogen deposition is hypothesised to induce microclimatic cooling through promoting increased vegetation cover ${ }^{19}$. However, our results were robust to the inclusion of a nitrogen deposition control; and changes in Leaf Area Index over the study period were not sufficiently correlated with heterogeneity in microclimatic heterogeneity plays a greater role for species that are more sensitive to 
disproportionate benefit to populations most vulnerable to warming. First, for species in parts

127

of their geographic ranges with conditions close to their thermal optima, or where warming is increasing the availability of optimal thermal environments, greater spatial variation in microclimate could reduce the absolute availability of thermally suitable conditions, decreasing the viability of regional populations. In contrast, for species where warming is reducing the availability of thermally suitable conditions, microclimatic heterogeneity could benefit species, by providing sufficient spatial variation in climatic conditions to ensure that thermally suitable conditions are maintained in close proximity to existing populations ${ }^{21}$. The magnitude of warming that has occurred over the duration of our study is exceeded by finescale spatial differences in temperature (Supplementary Fig. 4), suggesting that localised movement would be sufficient for species to track changes in climatic conditions ${ }^{22}$. Another potential reason is that microclimatically heterogeneous regions are also associated with atypical climatic conditions ${ }^{23}$ that are more resistant to invasion ${ }^{24}$. Populations in such locations may thus experience reduced competitive exclusion. A further reason is that, even within relatively small regions, contrasting terrain results in remarkably variable rates of warming, implying that heterogeneity in microclimate is also associated with heterogeneity in rates of warming ${ }^{12}$. In consequence, species threatened by climate change in regions of high microclimatic variability may be more likely to persist for longer in localities experiencing reduced rates of warming.

Given finite resources, conservation practitioners are urgently assessing the relative vulnerability of species to climate change. Assessments of species vulnerability have focussed on comparisons of sensitivity, adaptive capacity and exposure to climate change $\mathrm{e}^{25,26}$, but have often omitted the potential for local variation in climate to reduce exposure to adverse climatic changes. Variation in rates of warming and increased availability of suitable 
local climates associated with microclimatic heterogeneity could potentially reduce exposure to climate change. Species identified as being most vulnerable are typically those that are predicted to have narrow climatic associations and little or no capacity to expand elsewhere ${ }^{27}$. However, modelled estimates of climatic associations, range shifts and extirpation risk made using coarse-resolution climate data inevitably fail to account for fine-scale variation in climate ${ }^{8,17}$ and may thus over-estimate the distance over which species must move. The prediction that species will be extirpated from large parts of their range is prevalent in the scientific literature, leading to debate regarding approaches to avert species loss from climate change. Proposals include habitat restoration ${ }^{15}$, the redesign of protected area networks ${ }^{9}$, and assisted colonisation ${ }^{28}$, but competing demands on land-use and on economic resources render such approaches difficult to achieve. In situ conservation measures are typically easier to implement, and if targeted at refugial locations with high microclimatic heterogeneity, could help to reduce extinction risk as regional climates become unsuitable. While management at these locations will require many of the same approaches used to conserve species as elsewhere, placing greater emphasis on enhancing local persistence gains time for systems to adapt, and for managers and society to develop longerterm solutions ${ }^{4}$. Ultimately, the protection of microrefugia is a way to prioritise locations for management given limited resources. What will differ is the emphasis on protecting, maintaining, and fostering the features that create microclimate heterogeneity, and on enhancing the local persistence of species in the face of ongoing climate change, alongside those regional actions that may already be in place.

Nevertheless, estimates of extinction risk from climate change demonstrate that high population-level losses have already been observed ${ }^{29}$. The magnitude of anthropogenic warming to date is approximately half that expected by $2050^{30}$, and biodiversity losses are predicted to accelerate with increased warming ${ }^{7}$. In consequence, the results of our study 
175 should not be interpreted to imply that safeguarding species against the effects of climate

176 change is any less urgent, but rather that protection and appropriate management of

177 microrefugia could form important elements of wider efforts to adapt nature conservation to 178 climate change, at least in the short term ${ }^{4}$. 


\section{References}

1801 Dawson, T. P., Jackson, S. T., House, J. I., Prentice, I. C. \& Mace, G. M. Beyond predictions: biodiversity conservation in a changing climate. Science 332, 53-58

182 (2011).

183

2 Stewart, J. R., Lister, A. M., Barnes, I. \& Dalén, L. Refugia revisited: individualistic responses of species in space and time. P. Roy. Soc. Lon. B. Bio. 277, 661-671 (2010). Moritz, C. \& Agudo, R. The Future of Species Under Climate Change: Resilience or Decline? Science 341, 504-508 (2013).

187

4 Morelli, T. L. et al. Managing Climate Change Refugia for Climate Adaptation. PLoS ONE 11 (8): e0159909 (2017).

Settele, J., Bishop, J. \& Potts, S. G. Climate change impacts on pollination. Nat. Plants 2, DOI: 10.1038/nplants.2016.92 (2016).

191

6 Greenwood, O., Mossman, H. L., Suggitt, A. J., Curtis, R. J. \& Maclean, I. M. D. Using in situ management to conserve biodiversity under climate change. J. Appl. Ecol. 53, 885-894 (2016). (2015).

1968 Potter, K. A., Woods, A. H. \& Pincebourde, S. Microclimatic challenges in global change biology. Glob. Change Biol. 19, 2932-2939 (2013). Araújo, M. B., Alagador, D., Cabeza, M., Nogués-Bravo, D. \& Thuiller, W. Climate change threatens European conservation areas. Ecol. Lett. 14, 484-492 (2011).

20010 Hylander, K., Ehrlén, J., Luoto, M. \& Meineri, E. Microrefugia: not for everyone. Ambio 44, 60-68 (2015). 
20211 Pearce-Higgins, J. W. et al. A national-scale assessment of climate change impacts on species: Assessing the balance of risks and opportunities for multiple taxa. Biol. Conserv. 213, 124-134 (2017). climate change: modelling fine-scale spatial variation in biologically meaningful rates of warming. Glob. Change Biol. 23, 256-268 (2017).

Keating, K. A., Gogan, P. J., Vore, J. M. \& Irby, L. R. A simple solar radiation index for wildlife habitat studies. J. Wildlife Manage. 71, 1344-1348 (2007).

Bennie, J., Huntley, B., Wiltshire, A., Hill, M. O. \& Baxter, R. Slope, aspect and climate: spatially explicit and implicit models of topographic microclimate in chalk grassland. Ecol. Model. 216, 47-59 (2008).

Oliver, T. H. et al. Interacting effects of climate change and habitat fragmentation on drought-sensitive butterflies . Nat. Clim. Change 5, 941-945 (2015).

Robinson, R. A. \& Sutherland, W. J. Post-war changes in arable farming and biodiversity in Great Britain. J. Appl. Ecol. 39, 157-176 (2002).

Lenoir, J., Hattab, T. \& Guillaume, P. J. Climatic microrefugia under anthropogenic climate change: implications for species redistribution. Ecography 40, 253-266 (2017).

Frey, S. J. K. et al. Spatial models reveal the microclimatic buffering capacity of oldgrowth forests. Sci. Adv. 2, e1501392 (2016).

Wallis De Vries, M. \& Van Swaay, C. Global warming and excess nitrogen may induce butterfly decline by microclimatic cooling. Glob. Change Biol. 12, 1620-1626 (2006). landscapes promote population stability. Ecol Lett. 16, 473-484 (2010). 
22721 Somero, G. The physiology of climate change: how potentials for acclimatization and genetic adaptation will determine 'winners' and 'losers'. J. Exp. Biol. 213, 912-920

229 (2010).

22 Lenoir, J. et al. Local temperatures inferred from plant communities suggest strong spatial buffering of climate warming across Northern Europe. Glob. Change Biol. 19, 1470-1481 (2013). Ashcroft M. B., Gollan, J. R., Warton, D. W. \& Ramp, D. A novel approach to quantify and locate potential microrefugia using topoclimate, climate stability, and isolation from the matrix. Glob. Change Biol. 18, 1866-1879 (2012).

24 Bennie, J. J., Hill, M. O., Baxter, R. \& Huntley, B. Influence of slope and aspect on long-term vegetation change in British chalk grasslands. J. Ecol. 94, 355-368 (2006).

25 Pacifici, M. et al. Assessing species vulnerability to climate change. Nat. Clim. Change 5, 215-224 (2015).

26 Butt N. et al. Challenges in assessing the vulnerability of species to climate change to inform conservation actions. Biol. Conserv. 199, 10-15 (2016).

27 Thomas, C. D. et al. A framework for assessing threats and benefits to species responding to climate change. Methods Ecol. Evol. 2, 125-142 (2011).

28 Thomas, C. D. Translocation of species, climate change, and the end of trying to recreate past ecological communities. Trends Ecol. Evol. 26, 216-221 (2011).

29 Maclean, I. M. D. \& Wilson, R. J. Recent ecological responses to climate change support predictions of high extinction risk. Proc. Natl. Acad. Sci. USA 108, 12337$12342(2011)$.

30 Stocker, T. F. et al. Climate Change 2013: the Physical Science Basis: Working Group I Contribution to the Fifth Assessment Report of the Intergovernmental Panel on Climate Change. (Cambridge Univ. Press, Cambridge, 2014). 
Correspondence and requests for materials should be addressed to A.J.S., R.J.W. or

I.M.D.M.

254

Acknowledgements We thank the many people, predominantly volunteers, who submitted data to the Botanical Society of Britain and Ireland, British Bryological Society, Butterfly Conservation, the Ground Beetle Recording Scheme, the Soldier Beetle Recording Scheme, Longhorn Beetle Recording Scheme and the UK Ladybird Survey, as well as the coordinators of those schemes. Thanks also to the UK Met Office, Natural England, Environment Agency, CEH, Defra and NASA for data access. Iain Stott, Richard Inger, América Paz Durán, Kevin Gaston and five referees provided helpful comments on drafts of the manuscript. The work was funded by Natural England, and by NERC grant NE/L00268X/1 to RJW and IMDM.

264

Author Contributions A.J.S. conducted the analyses. I.M.D.M., N.J.B.I., N.A.M., M.D.M.,

S.D., H.Q.P.C. and R.J.W. conceived the work and supervised analyses. A.J.S, I.M.D.M. and

R.J.W. wrote the manuscript with contributions from the whole team. C.M.B., A.G.A., T.A., J.J.B., J.J.H., R.F. and K.J.W. provided data and expert guidance.

269

Competing financial interests The authors have no competing financial interests to declare. 5666, JJB: 0000-0003-4394-2041, HQPC: 0000-0002-5136-378X, SD: 0000-0003-33649255, RF: 0000-0001-6992-3522, NJBI: 0000-0002-4869-8052, MDM: 0000-0002-79785554, KJW: 0000-0002-5751-8623, RJW: 0000-0003-4477-7068, IMDM: 0000-0001-8030276 9136. 


\section{Biological response data}

279 We obtained data on the distribution of species from the Botanical Society of Britain and Ireland, the British Bryological Society, Butterflies of the New Millennium, the National Moth Recording Scheme, and the National Recording Schemes for Ground Beetles, Soldier Beetles, Longhorn Beetles, and Ladybirds. All these organisations accept records from either taxonomic specialists or the general public, and any unusual records undergo a vetting process to establish their veracity ${ }^{31}$. We analysed data on 430 species identified as 'climatethreatened' in a recent climate change risk assessment for our study region ${ }^{11}$ in which projected responses to future climate change to 2100 were assessed, and for which adequate data were available (see below).

To establish patterns of extirpation over a period of warming, we aggregated the data into two time periods. For vascular plants and bryophytes these periods were 1970-1986 and 1987-2009, and for the lepidopterans and coleopterans, 1970-1989 and 1990-2009. These periods correspond to comprehensive national coverage, often associated with the production of atlases for the corresponding flora and fauna ${ }^{32-35}$, during which coordinators sought to maximise observer coverage of $10 \mathrm{~km}$ x $10 \mathrm{~km}$ grid squares (hectads). We restricted our analysis to species which were recorded in more than 100 of the $10 \mathrm{~km}$ grid squares in the first time period, as long as the same $10 \mathrm{~km}$ square was visited by recorders for that taxonomic group's recording scheme in the second time period. Absences are not explicitly recorded within these schemes, so 'extirpations' from grid squares are here defined as a species being recorded as present during the first period, but not in the second.

To account for possible influences of variation in recorder effort on patterns of apparent extirpation, we calculated the number of unique recorder visits to each $10 \mathrm{~km}$ grid 
recorder effort in all analyses (Supplementary Fig. 1a). The risk that extirpations were an artefact of recorder effort was reduced by the fact that there were 3.5 times more records submitted for the second period than the first (Supplementary Fig. 1b, c). To reduce the risk of falsely assigned absences further, we only included grid squares in analysis if at least one species within a respective taxon's recording scheme was recorded in the target grid square during the second time period (i.e. inferred extirpation required other species from the same taxonomic group to have been recorded). For the vast majority of grid squares and taxa, the number of distribution records was higher in the second period than the first (Supplementary Fig. 2). In addition to using recorder effort as a control, we checked whether changes to recorder effort could have confounded our analyses, by assessing correlations between recording change over time and microclimatic heterogeneity (Supplementary Table 2). Seven of the eight recording schemes showed a weak negative correlation, suggesting that recorder effort tended to increase more in grid squares with lower microclimatic heterogeneity. In other words, a loss of species from the less microclimatically heterogeneous grid squares would be very unlikely to result from variation in detection over time.

\section{Climate change variables}

Monthly mean $5 \times 5 \mathrm{~km}$ gridded temperature data were obtained from the UK Met Office ${ }^{36}$ to calculate the mean summertime (June, July, August) temperature of each $10 \mathrm{~km}$ x $10 \mathrm{~km}$ grid square in each year within the period of study (1970-2009). Summertime temperatures were selected to represent the main influences of climate on the population dynamics of our study species. Linear models were then fitted to the climate data for each grid square and the slopes of these regressions $\left(\Delta^{\circ} \mathrm{C} /\right.$ year $)$ were derived and utilised for subsequent analyses. The same methods were used to derive the change in total summertime precipitation in each grid square ( $\Delta \mathrm{mm} /$ year), which was included as a control variable. Although we did not limit our 
analysis to grid squares in which the climate has warmed, in practice almost all grid squares did experience a warming trend over our study period.

\section{Microclimatic heterogeneity}

To derive a proxy for landscape heterogeneity in topographically-driven temperature microclimates, a three-arc second ( $\sim 90 \mathrm{~m})$ horizontal resolution Digital Elevation Model (DEM) was obtained from the Shuttle Radar Topography Mission ${ }^{37}$ and resampled and coarsened to $100 \times 100 \mathrm{~m}$ resolution using bilinear interpolation. The proportion of direct beam radiation incident on the surface of each grid square of the DEM, hereafter referred to as the solar index, was calculated using a method that accounts for slope, aspect, and topographic shading ${ }^{12}$. The mean of hourly values over the 24 hours of 21 st June was used as this provides a good proxy of near-ground daily mean and maximum temperatures across the growing season (see below). Third and finally, the standard deviation of solar index values in each $10 \mathrm{~km}$ grid square was calculated to represent heterogeneity in the thermal microclimate.

To verify that solar index values are a good proxy for the effects of topography on fine-scale microclimatic temperatures, we tested them against the outputs of a microclimate model that accurately estimates near-ground temperatures at hourly intervals ${ }^{12}$ (mean error of model $=1.21^{\circ} \mathrm{C}$ ). For a $225 \mathrm{~km}^{2}$ part of our study region (The Lizard Peninsula in Cornwall), we derived surface temperatures over a 20 year period (1990-2009) at a spatial resolution of $100 \times 100 \mathrm{~m}$ and at hourly temporal resolution, before calculating the mean and mean daily maximum temperature of each $100 \mathrm{~m}$ grid square across the growing season of April to September (Supplementary Figs. 3 \& 4). We calculated the standard deviation in temperatures of all the $100 \mathrm{~m}$ grid squares $(\mathrm{n}=100)$ in each $1 \times 1 \mathrm{~km}$ square (separately for 
maximum and mean temperatures) and compared these values to the standard deviation in solar index values in corresponding grid cells.

We found the solar index to be a reliable proxy of both mean and maximum temperatures across the growing season. More than half of the spatial variation in the mean $\left(\mathrm{r}^{2}=0.72, \mathrm{p}<0.0001\right)$ and maximum $\left(\mathrm{r}^{2}=0.73, \mathrm{p}<0.0001\right)$ temperature anomalies is explained by the solar index, our proxy for the thermal microclimate (Supplementary Figs. 3 $\& 4)$.

However, it should be noted that the microclimates experienced by organisms are influenced both by the effects of topography and by the effects of vegetation structure ${ }^{17,18}$, and that increases in vegetation cover can dampen the effects of warming on species ${ }^{38}$. Whilst our main aim was to address the possible buffering effects of topographic microclimates over the scales which they are likely to have the dominant effects on rates and patterns of warming ${ }^{12}(100 \mathrm{~m}-10 \mathrm{~km})$, we conducted a supplementary analysis to examine possible confounding effects of changes in vegetation cover on our results. We used the 0.05 degree $(\sim 5 \mathrm{~km})$ dataset of daily Leaf Area Index (LAI) from the National Oceanic and Atmospheric Administration ${ }^{39}$ to calculate the mean LAI in each $10 \mathrm{~km}$ grid square from 1982 (the earliest date for which it is available) until 1989, and for 1990 to 2009 , and calculated the log proportional change between the two periods (Supplementary Fig. 5). The weak positive correlation between change in LAI and modelled heterogeneity in topographic microclimate $(r=+0.07$, d.f. $=1300, p=0.02$; Supplementary Table 2$)$ suggests that changes to vegetation cover have not confounded our results. As a further check we also tested the ability of change in LAI to explain the overall pattern of extirpations observed. We fitted Generalised Linear Mixed Models (GLMMs) to the datasets from plant and insect groups separately, with LAI change included as a fixed effect, and species identity included as a random intercept. LAI change explained less than $0.04 \%$ of the variation in extirpation probability in either group 
376 (the 'marginal r-squared' statistic), giving us further confidence that our conclusions are 377 robust.

\section{Control variables}

380

As well as the control for recorder effort, we included a set of control variables in all of our analyses to account for additional factors which could have influenced the patterns of persistence and extirpation observed across $10 \mathrm{~km}$ grid squares. We note that species could have been lost from $10 \mathrm{~km}$ grid squares because of a range of independent or interacting factors, including climate change, habitat loss and pollution.

To control for possible confounding effects of greater agricultural intensity in flatter landscapes (with lesser heterogeneity in topographic microclimates) we calculated a measure of agricultural intensity for all $10 \mathrm{~km}$ grid squares. The Centre for Ecology and Hydrology's 2007 land cover (vector) map ${ }^{40}$ was sampled to a grid square resolution of 1 x $1 \mathrm{~km}$, and the proportion of each $10 \times 10 \mathrm{~km}$ grid square that was 'Arable and horticulture' or 'Improved grassland' calculated. Determining change in these land cover classes was not possible for the period of time covered by our analyses, as the classification method used to derive successive land-cover maps of the same region has been modified substantially over time ${ }^{41,42}$. As an indication that our measure of agricultural intensity is representative of spatial patterns in land-use intensification over a time period relevant to the changes observed to species distributions, we also calculated a measure of land development (proportion land cover change to arable or urban) for each $10 \mathrm{~km}$ grid square (Supplementary Fig 5c). The land development measure was based on a digitisation of land cover maps using data from 1925$1948^{43}$ compared with land cover information from $1990^{44}$, and was positively correlated with our measure of agricultural intensity $(r=0.52$, d.f. $=1300, p<0.00001)$. Most of the patterns in land development from 1948-1990 comprise conversion of land to agricultural ( $r$ 
$401=0.72$, d.f. $=1300, p<0.00001)$, with the patterns only weakly correlated with changes to $402 \operatorname{urban}(r=0.15$, d.f. $=1300, p<0.00001)$. In addition, the majority of this intensification of 403 land use in England and Wales is estimated to have occurred between 1925 and 1978, based 404 on a comparison of the 1925-1948 land cover data and surveys conducted in the UK 405 Countryside Survey in 1978, 1990, 1998 and 2007 ${ }^{45}$ (Note: the 1978-2007 data cannot be used to estimate change in all $10 \mathrm{~km}$ grid squares, as the surveys were not exhaustive). Given that most land cover changes pre-dated our period of study, we use agricultural intensity as the control that is most likely to be relevant for distribution changes observed between the two c. 20 year distribution recording periods before and after the end of the 1980s. Although the land cover categories included in agricultural intensity represent the classes we expect to be most deleterious to our study taxa, it is important to emphasise that they are only simplified representations of the effects we seek to control for, and do not represent all the components of land-use intensification that could potentially be drivers of change ${ }^{16}$.

Because anthropogenic nitrogen deposition has been responsible for changes in community composition $^{42}$, and can also modify species' responses to climate change ${ }^{19}$, we also included estimates of nitrogen deposition as a control in our models. Spatial data for 417 England are available via outputs from Defra's Concentration Based Estimated Deposition (CBED) model $^{46}$ from 2004 onwards, which we used to calculate the mean annual total nitrogen deposition ( $\mathrm{kg} \mathrm{N} /$ hectare / year) between 2004 to 2009 in each $10 \mathrm{~km}$ grid square. Because there is a relative lack of flatter areas on higher ground in the English landscape, heterogeneity in topographic microclimates could also be confounded by elevation. Hence, the mean elevation of each $10 \times 10 \mathrm{~km}$ grid square, derived from the $100 \mathrm{x}$ $100 \mathrm{~m}$ resolution DEM, was also included as a control variable in models. Finally, to account 424 for extirpations driven by moisture changes, the annual change in total precipitation for each $10 \mathrm{~km}$ grid square was also included as a control. 
427 Analyses

428 The extirpation or persistence of each species in each $10 \mathrm{~km}$ grid square was modelled as a

429 function of temperature increase, heterogeneity in topographic microclimate and an

430 interaction between these two variables, with agricultural intensity, nitrogen deposition, precipitation change, the mean elevation of each grid square and recorder effort (logtransformed) included as control variables. We modelled extirpation/persistence using general estimating equations ${ }^{47}$, which account for correlations within spatial clusters of data points by parameterising a correlation matrix, while correlations between clusters are assumed to be zero. Spatial clusters were identified automatically using the methods outlined in Dormann et al. ${ }^{48}$ and Carl \& Kühn ${ }^{49}$.

To classify species according to their response to warming, microclimate heterogeneity and the interaction between the two (Fig. 1; Supplementary Table 1), separate models were constructed for each species. A forward selection procedure was used to identify the response to each term; i.e. a response to heterogeneity was assessed only for those species responding to warming, and a response to the interaction between microclimate heterogeneity and warming was assessed only for those species responding to both these terms individually. We considered a species to be 'responding' to a variable (Fig. 1) only if the inclusion of that variable resulted in improved model performance, assessed using Pan's Quasi Information Criterion $^{50}$. Analyses were performed using the geepack ${ }^{51}$ and $\mathrm{MESS}^{52}$ packages for $\mathrm{R}^{53}$. To test the sensitivity of our results to alternative model selection procedures, we also conducted full multi-model inference for each species, whereby all possible responses to climate and microclimate heterogeneity were tested. In this 'full QIC' approach, the model with the lowest QIC was selected as the final model ${ }^{54}$. For species in which the best model included warming, microclimate, and/or the interaction between the two, there was a high 
451 level of support for the conclusions from the forwards approach (Supplementary Fig. 6). Of 452 species responding to warming, $70 \%$ of plants were affected negatively by warming in the 453 full QIC approach, whereas only $40 \%$ of insects were affected negatively. Of species where 454 the best models for persistence versus extirpation included an interaction between 455 microclimate and warming, $69 \%$ of plants and $57 \%$ of insects showed a positive interaction, suggesting a beneficial effect of microclimatic heterogeneity for species whose patterns of extirpation were affected by climate change. For both plant and insect species in which the lowest QIC included all predictor variables and interactions, the most prevalent response was that most indicative of a buffering effect, showing a negative effect of warming, a positive effect of microclimatic heterogeneity, and a positive interaction between the two (Type 5 in Fig 1c and Supplementary Fig. 6).

Finally, to estimate the size of the microclimate buffering effect, we used the full model for each species (including all variables) to predict variation in extirpation risk at various levels of warming and microclimatic heterogeneity, holding the control variables at their median value (Fig. 2). Grid squares that were colonised between the two time periods were excluded from analyses.

\section{Data availability}

The datasets that support this study are available from the following sources: biological response data via NBN (https://nbnatlas.org), climate change data via the UK Met Office

471 (http://catalogue.ceda.ac.uk/uuid/87f43af9d02e42f483351d79b3d6162a), elevation data via USGS (https://www2.jpl.nasa.gov/srtm/cbanddataproducts.html), LAI vegetation cover data via NOAA (https://data.nodc.noaa.gov/cgi-bin/iso?id=gov.noaa.ncdc:C00898), land cover data under licence via EDINA (https://digimap.edina.ac.uk), nitrogen deposition data via 475 CEH (http://www.pollutantdeposition.ceh.ac.uk). 
477 Methods references

47831 Pocock, M. J., Roy, H. E., Preston, C. D. \& Roy, D. B. The Biological Records 479 Centre: a pioneer of citizen science. Biol. J. Linnean Soc. 115, 475-493 (2015).

48032 Heath, J., Pollard, E. \& Thomas, J. A. Atlas of Butterflies in Britain and Ireland. $481 \quad$ (Viking, New York, 1984).

48233 Asher, J. et al. The Millennium Atlas of Butterflies in Britain and Ireland. (Oxford $483 \quad$ Univ. Press, Oxford, 2001).

48434 Perring, F. H. \& Walters, S. M. Atlas of the British flora. (Thomas Nelson \& Sons, $485 \quad$ London, 1962).

48635 Preston, C. D., Pearman, D. A. \& Dines, T. D. New Atlas of the British and Irish 487 Flora. An Atlas of the Vascular Plants of Britain, Ireland, the Isle of Man and the $488 \quad$ Channel Islands. (Oxford Univ. Press, Oxford, 2002).

48936 Jenkins, G. J. et al. The Climate of the United Kingdom and Recent Trends (Met $490 \quad$ Office Hadley Centre, Exeter, 2007).

49137 Farr, T. G. et al. The shuttle radar topography mission. Rev. Geophys. 45, RG2004 $492 \quad$ (2007).

49338 De Frenne, P. et al. Microclimate moderates plant responses to macroclimate warming. Proc. Natl. Acad. Sci. USA 110, 18561-18565 (2013).

39 Claverie, M., Vermote, E., \& NOAA CDR Program. NOAA Climate Data Record (CDR) of Leaf Area Index (LAI) and Fraction of Absorbed Photosynthetically Active Radiation (FAPAR), Version 4. NOAA National Centers for Environmental Information. doi:10.7289/V5M043BX (2014) [Access date: 06/01/2018]. Lancaster, 2011). 
$50141 \quad$ Mair, L. et al. Abundance changes and habitat availability drive species' responses to $502 \quad$ climate change. Nat. Clim. Change 4, 127-131 (2014).

50342 McClean, C. J., van den Berg, L. J. L., Ashmore, M. R. \& Preston, C. D. Atmospheric 504 nitrogen deposition explains patterns of plant species loss. Glob. Change Biol. 17, $505 \quad 2882-2892(2011)$

50643 Stamp, L. D. The land of Britain: its use and misuse. London, UK: Longmans, Green $507 \quad$ and Co. (1948).

$50844 \quad$ Fuller, R. M., Groom, G. B. \& Jones, A.R. Land cover map of Great Britain. An 509 automated classification of Landsat Thematic Mapper data. Photogrammetric $510 \quad$ Engineering and Remote Sensing 60, 5 (1994).

51145 Baude, M. et al. Historical nectar assessment reveals the fall and rise of floral $512 \quad$ resources in Britain. Nature 530, 85-88 (2016).

51346 Dore, A. J. et al. Modelling the atmospheric transport and deposition of sulphur and 514 nitrogen over the United Kingdom and assessment of the influence of $\mathrm{SO}_{2}$ emissions 515 from international shipping. Atmos. Environ. 41, 2355-2367 (2007).

51647 Liang, K.-Y. \& Zeger, S. L. Longitudinal data analysis using generalized linear 517 models. Biometrika 73, 13-22 (1986).

51848 Dormann, C. et al. Methods to account for spatial autocorrelation in the analysis of 519 species distributional data: a review. Ecography 30, 609-628 (2007).

52049 Carl, G. \& Kühn, I. Analyzing spatial autocorrelation in species distributions using 521 Gaussian and logit models. Ecol. Model. 207, 159-170 (2007).

$52250 \quad$ Pan, W. Akaike's information criterion in generalized estimating equations. $523 \quad$ Biometrics 57, 120-125 (2001).

$52451 \quad$ Halekoh, U., Højsgaard, S. \& Yan, J. The R package geepack for generalized estimating equations. J. Stat. Softw. 15, 1-11 (2006). 
$52652 \quad$ Ekstrom, C. MESS: Miscellaneous Esoteric Statistical Scripts. R package version 0.4527 3. http://CRAN.R-project.org/package=MESS (2012).

52853 R Development Core Team. R Project for Statistical Computing. http://www.r$529 \quad$ project.org (R Project, Geneva, 2017).

$53054 \quad$ Burnham, K. P. \& Anderson, D. R. Model selection and multimodel inference: $a$ $531 \quad$ practical information-theoretic approach. 2nd edn. Springer-Verlag, New York.

532 (2002). 
Fig. 1 Classification of plants (green) and insects (purple) by responses to warming and microclimatic heterogeneity. Species ( $\mathrm{n}=430$ ) were initially classified by their response to warming (panel a). For those species affected by warming $(n=321)$, the species' response is classified as positive or negative, and their response to microclimate heterogeneity (in addition to warming) assessed (b). For those species affected by both warming and microclimate heterogeneity $(\mathrm{n}=228)$, the effects of an interaction between warming and heterogeneity were assessed, and each species exhibiting a response was assigned to one of eight response types (c). Asterisks indicate response types indicative of microclimate buffering.

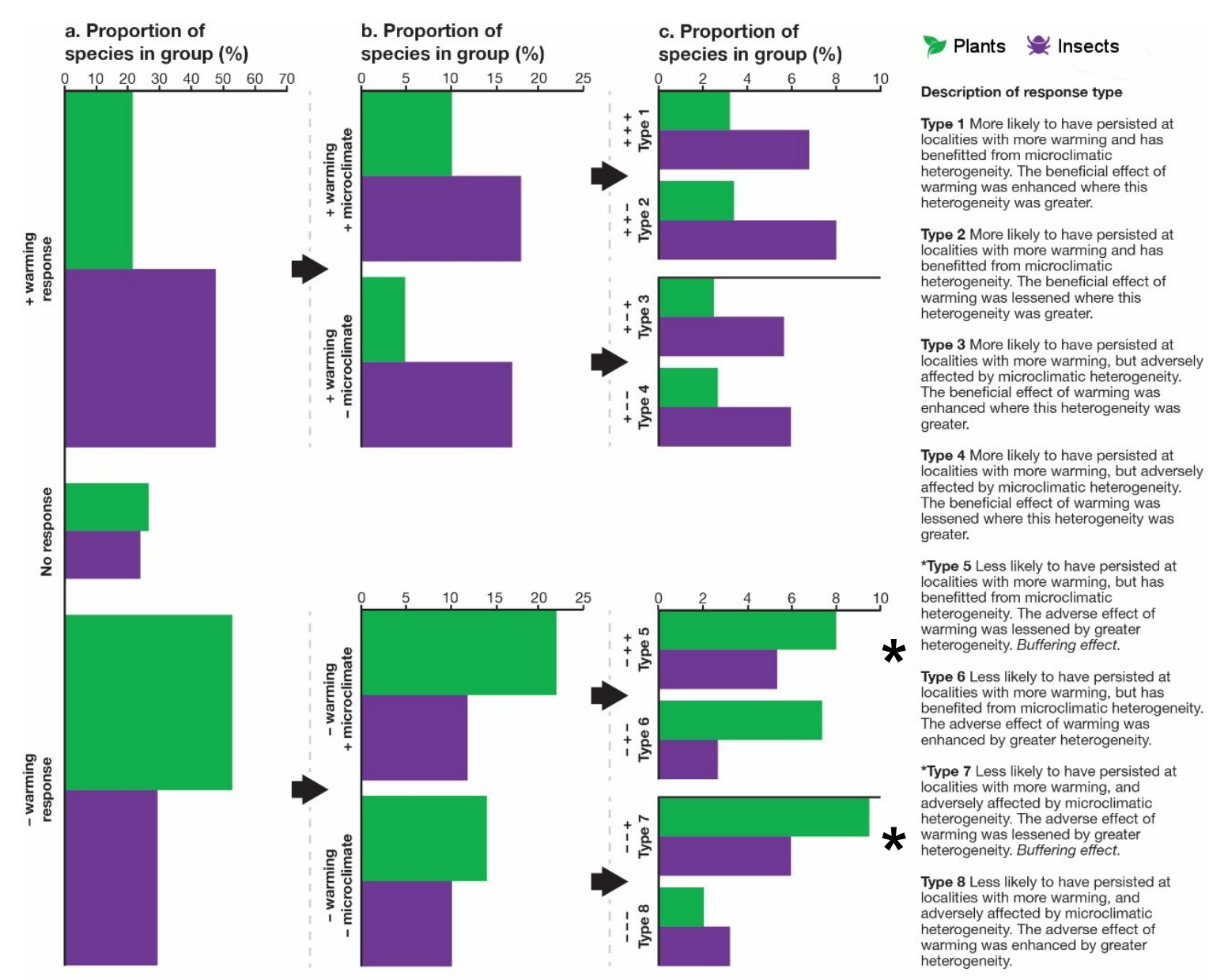


Fig. 2 Modelled change in extirpation risk for each species as a function of warming and microclimate heterogeneity. The relative frequency of warming in each grid square is shown in (a). In (b-k), the modelled differences in extirpation risk between areas of high (95th percentile) microclimatic heterogeneity and low (5th percentile) microclimatic heterogeneity are shown for various levels of warming, separately for plants (b-f) and insects (g-k). Red coloration denotes species adversely affected by warming, for which the inclusion of a warming term improved model performance. Orange coloration denotes species models that exhibited a negative response to warming, but for which the inclusion of a warming term did not improve model performance. Grey coloration denotes species that exhibited a positive relationship to warming.

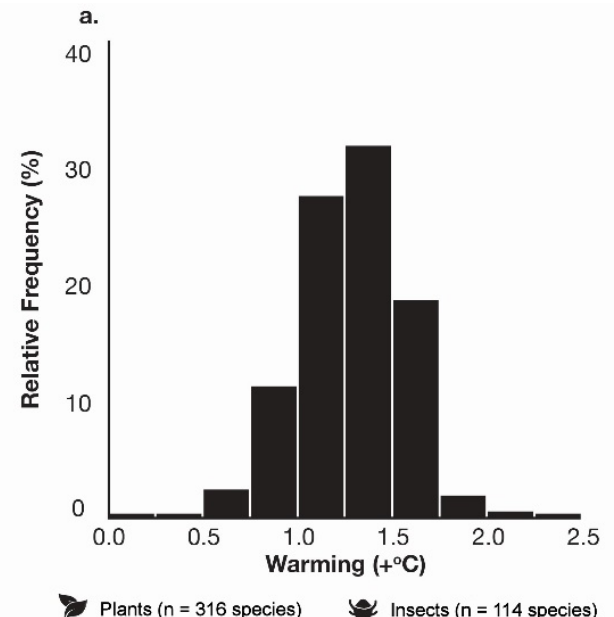

b.

$95^{\text {th }}$ percentile - Very high warming
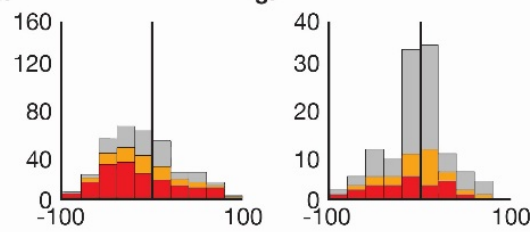

$75^{\text {th }}$ percentile - High warming

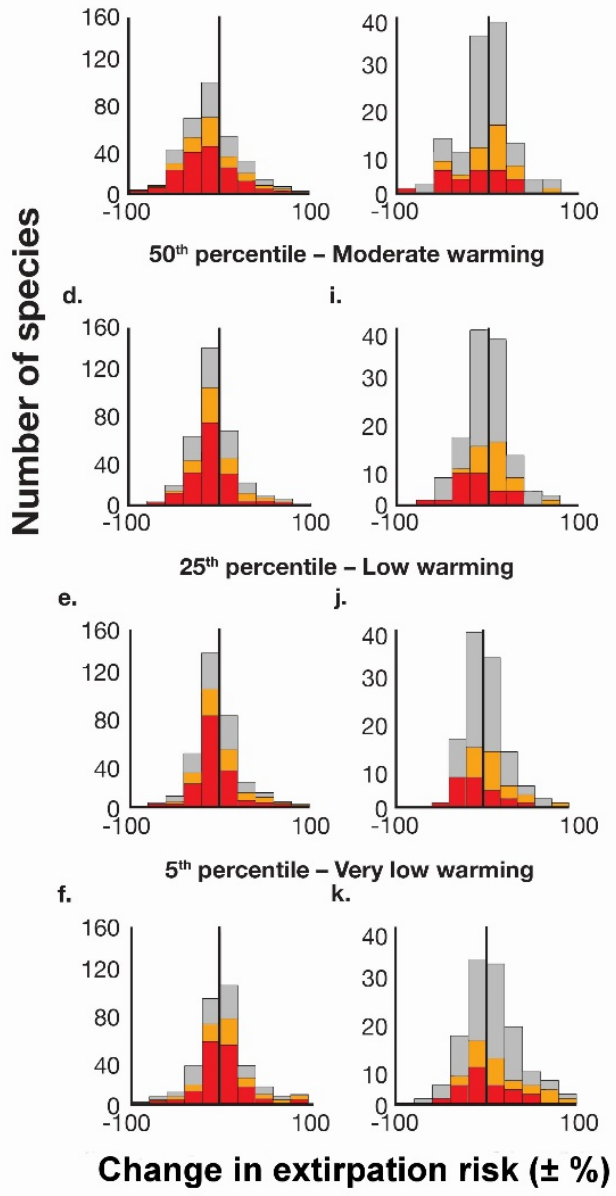

